\title{
Biology and Philosophy's transition to continuous publication
}

\author{
Michael Weisberg ${ }^{1}$
}

Published online: 16 March 2018

(C) Springer Science+Business Media B.V., part of Springer Nature 2018

I am very pleased to announce that Biology and Philosophy has adopted the Continuous Article Publication model. This model erases the distinction between articles that are "Online First" and the final published version of the article. As soon as articles are accepted, typeset, and proofread, they will be posted online in their final form. Printed copies of the journal will continue to be produced, but the articles in these printed copies will simply appear in the sequence of which they have been accepted.

Although moving to continuous publication has many advantages for authors and editors, there is a subtle change that will affect citation practices. In continuous publication, the best way to cite an article is to use its Digital Object Identifier (DOI). This is a persistent pointer to the article, in a form standardized by the International Organization for Standardization (ISO). For example, the DOI of this editorial is: https://doi.org/10.1007/s10539-018-9611-9.

At this time, DOIs resolve to journal URLs and other publication metadata that allow the article to be located. But the idea is that DOIs are permanent, and will continue to point to the article regardless of technological changes.

Please note that all articles will begin with page number 1 . This makes it essential to include the DOI in the citation. For example, in the format we use at this journal, the citation for this article will be:

Weisberg M (2018) Biology and Philosophy's Transition to Continuous Publication. Biol Phil. DOI: https://doi.org/10.1007/s10539-018-9611-9.

Michael Weisberg

weisberg@phil.upenn.edu

1 Department of Philosophy, University of Pennsylvania, 433 Cohen Hall, Philadelphia, PA 19104-6304, USA 